\title{
Construindo a Caixa-Preta da Dualidade Onda-Partícula de Louis de Broglie em Sala de Aula
}

Building the Black Box of Louis de Broglie's Wave-Particle Duality in the Classroom

(D) Thiago Silva Peron, Andreia Guerra

Palavras-chave Resumo Apresentamos neste artigo os resultados de uma pesquisa, Ensino de Ciências; dividida em uma parte teórica e outra empírica, que teve por foco História Cultural a discussão da validação do conceito de dualidade onda-partícula das Ciências; proposto por Louis de Broglie, em 1923, a partir do estudo da Sociologia e prática científica de divulgação entre pares por meio da publicação Filosofia de Bruno de artigos científicos. O estudo partiu do olhar para as práticas Latour; Validação científicas, proposto pela vertente historiográfica da História Cultural do conhecimento; da Ciência. Dessa forma, a investigação das publicações mencionadas

Dualidade ocorreu a partir da análise das citações em torno do conceito por elas onda-partícula. apresentado e pela estabilização daquele conhecimento. A Sociologia e Filosofia de Bruno Latour orientou-nos neste percurso, no sentido de agregar ao estudo das práticas científicas os diversos agentes envolvidos na construção do conceito de dualidade de de Broglie, sejam eles agente humanos ou não-humanos. $O$ resultado da pesquisa teórica guiou o desenvolvimento da parte empírica da investigação que foi implementada em aulas de Física da educação básica. $\mathrm{O}$ objetivo dessa pesquisa foi analisar quais questões sobre a validação de um conhecimento científico emergem em aulas de ciências, quando o trabalho tem por eixo condutor a discussão do processo de validação do conhecimento científico, delimitado pela divulgação científica entre pares. Os resultados apontam que os estudantes problematizaram visões de ciência por eles manifestadas no início da pesquisa, dentre estas, a de que provas matemáticas e experimentais são os únicos caminhos para validar o conhecimento científico. 
Keywords Abstract In this article, we present the results of a research study Science teaching; divided into a theoretical and an empirical part, which focuses on Cultural History discussing the validation of the wave-particle duality concept proposed of Sciences; Bruno by Louis de Broglie in 1923, based on investigation of scientific articles. Latour's Sociology The historiographical aspect of Cultural History of Science and Bruno and Philosophy; Latour's Sociology and Philosophy guided the study. Thus, we carried Knowledge on the aforementioned investigation from mentions in scientific validation; journals, discussing how did they develop the knowledge on De Wave-particle Broglie's concepts considering the humans and non-humans agents duality. involved in the process. From the analysis, we develop an empirical investigation that was implemented in Physics classes, where we analyzed which questions about validation of scientific knowledge emerged, as the concept of scientific dissemination of knowledge was presented. The results indicate that students call into question their own prior views about scientific production such as that scientific knowledge is only validated from mathematical propositions and experimental tests.

\section{Introdução}

O ensino de ciências é considerado um dos caminhos para se discutir o papel da ciência na sociedade e o seu processo de construção (Martins, 2007; Allchin, 2013; Schiffer \& Guerra, 2015). Encontramos na literatura uma defesa de que devemos abordar em salas de aula não somente os conceitos científicos estabelecidos, mas também questões sobre ciências (Milne, 2011; Allchin, 2011; Irzik \& Nola, 2011; Martins, 2015). Dentre outras abordagens, a utilização da História, Filosofia e Sociologia das Ciências (HFSC) no ensino é apresentada e defendida como um caminho para trazer à educação científica aquelas discussões (Matthews, 1994; Guerra et al., 2004; Martins, 2007; Höttecke \& Silva, 2011; Forato, 2011; Moura \& Guerra, 2016; Santos, 2018).

Em consonância ao que foi exposto, entendemos que o ensino de ciências deva promover debates sobre os processos de construção da ciência ou, nos termos de Bruno Latour (2011), a ciência em formação. Entendemos que o estudo da ciência em formação em aulas de ciências na educação básica permite aos estudantes se aproximarem do saber especializado (Tedesco, 2006), desenvolverem julgamentos sobre aquilo que a ciência virá a lhes oferecer (Auler, 2007; Acevedo-Diaz, 2009) e, sobretudo, compreender como as relações de poder na sociedade também se manifestam e se consolidam nas ciências (Santos \& Meneses, 2010; Moura, 2019).

Com base nessas considerações, esse estudo visa contribuir com o debate em torno ao ensino sobre as ciências a partir da discussão dos resultados de uma pesquisa implementada em aulas de Física desenvolvidas a partir de uma abordagem histórica, filosófica e sociológica. Dessa forma, foi necessário delimitar uma perspectiva historiográfica. Considerando que vislumbramos as ciências como cultura, e não algo que 
possui uma identidade singular que se insere em determinada cultura, a História Cultural das Ciências (HCC) foi a abordagem historiográfica adotada para conduzir o estudo aqui discutido (Burke, 2008; Pimentel, 2010). A partir desse aporte, compreendemos que as ciências, como qualquer outra manifestação cultural, possuem temporalidade e localidade, devendo, ser analisadas em conjunto com questões econômicas, geopolíticas, religiosas, artísticas e ambientais (Burke, 2008).

Essas considerações levaram-nos ainda a outro aporte teórico: a Sociologia e Filosofia das ciências de Bruno Latour (2001, 2012, 2013) (Latour \& Woolgar, 1997). O autor além de defender inexistências de fronteiras entre ciências, natureza e sociedade, aponta que para compreendermos a construção dos conceitos científicos é necessário contemplar simetricamente os elementos sociais e naturais, humanos e não humanos, presentes no fazer científico. Num processo tal que não se perca de vista as controvérsias entre os diversos agentes envolvidos (Latour, 2001).

Apoiados em resultados de pesquisa da área que discutem obstáculos para a implementação de abordagens históricas e a importância de se delimitar o que será trabalhado em sala de aula de acordo com o tempo didático (Forato, Martins \& Pietrocola 2011), buscamos analisar que questões sobre as ciências emergem em aulas de Física, quando o estudo sobre o processo de construção das ciências é feito tomando como eixo central da discussão uma questão específica. Os aportes teóricos delimitados nos levaram, então, a selecionar como questão específica o processo de validação do conhecimento científico delimitado a partir da divulgação científica entre pares.

Escolhemostrabalhar o tema validação do saber científico, pois trabalhos anteriores reforçaram estudos da área que indicam que estudantes se manifestavam apontando que as construções nas ciências ocorrem através de comprovações experimentais ou matemáticas e que seus resultados, quando seguem critérios metodológicos corretos, são irrefutáveis (Peron, Guerra \& Forato, 2011; Peron \& Guerra, 2017; Lederman \& Lederman, 2019).

Inspirados nesses resultados desenvolvemos a investigação em aulas de Física do terceiro ano do ensino médio integrado ao ensino técnico, de uma escola pública da rede federal de ensino. Diferentes caminhos e assuntos poderiam proporcionar discussões sobre o problema da validação do conhecimento científico. Considerando os referenciais teóricos adotados e o currículo mandatório da escola, trabalhamos o problema a partir do estudo de como o conceito de dualidade onda-partícula de Louis de Broglie (1892-1987) se tornou uma caixa-preta. Importante aqui destacar que referimonos à conceituação onda-partícula de uma entidade material (Cushing, 1994; Pessoa Jr, 2003) e não ao comportamento dual de uma radiação luminosa, cuja conceituação original não partiu de de Broglie e foi profundamente discutida por Rosa (2004), Martins e Rosa (2014) e Lima e colaboradores (2020). 
Caixa-preta, por sua vez, é definido por Latour (2011) como um conceito que, depois de debatido e sofrer algumas modificações, é usado e citado por cientistas, sem que se façam necessárias referências aos artigos e debates fundadores de tal conceito ${ }^{1}$. Para tal, empreendemos uma análise do movimento de citações dos trabalhos de de Broglie considerados fundadores do conceito de dualidade onda-partícula. Dessa forma, foi possível analisar como se deu a validação daquele conceito por outros cientistas, com destaque para o quando e onde as publicações ocorreram. Além disso, pudemos analisar o papel das revistas científicas em definir quais produtos das ciências serão divulgados e submetidos às críticas dos demais cientistas. E, também, como as citações que referenciam determinadas obras contribuíram para a validação de conceitos científicos.

A escolha de um tema de Física Moderna (FM) ocorreu porque, na escola em que a pesquisa foi desenvolvida, os temas daquele conteúdo são trabalhados nos últimos meses do ano letivo. A abordagem metodológica selecionada, a etnografia, pressupõe que o pesquisador deve se inserir no contexto da pesquisa, de forma a conhecer os sujeitos e códigos daquela cultura. De tal forma que a pesquisa desenvolvida neste artigo seria melhor aproveitada se ocorresse em uma turma de estudantes que o professor já estivesse familiarizado. Dentre os possíveis temas de FM, o conceito dualidade ondapartícula de de Broglie pareceu-nos o mais propício por uma série de razões.

A primeira razão para escolha da temática refere-se ao fato de o tópico não figurar entre os mais explorados nos estudos sobre ensino de ciências. Conteúdos da FM como os da Teoria da Relatividade Restrita, por exemplo, foram bastante abordados em pesquisas anteriores (Ostermann \& Moreira, 2000). Almejávamos, portanto, trabalhar em torno de algum conceito não tão estudado pela área e, dessa forma, apresentar contribuições que possam agregar novas discussões. $\mathrm{O}$ segundo pretexto foi por ser um conceito que tangencia trabalhos de outros autores do século XX, como os trabalhos de Albert Einstein (1879-1955), Max Karl Ernst Ludwig Planck (1858-1947) ou Erwin Rudolf Josef Alexander Schrödinger (1887-1961) (Martins \& Rosa, 2014), e alguns desses autores serem citados em outras temáticas de FM estudada naquela turma de

1 Entendemos, contudo, que a conceituação de Louis de Broglie sobre a dualidade onda-partícula diferencia da proposta estabelecida a partir da interpretação de Copenhague. Para o francês uma partícula seria ao mesmo tempo onda e matéria, "the 'particle' as a (mathematical) singularity in the center of an extended wave" (Cushing, 1994, p. 126), ao contrário da proposta estabelecida pela interpretação de Copenhague que reconhece que uma partícula ora se comporta como onda ora como matéria (Cushing, 1994). Isto não desqualifica a proposta de de Broglie ou a consolidação do conceito por ele proposto como sendo uma caixa-preta (conceito discutido na seção seguinte). O estabelecimento de uma caixa-preta dá-se após uma série de controvérsias em torno do conceito originalmente apresentado (Latour, 2011), de tal forma que o episódio estudado ilustra e acorda com o aporte teórico que adotamos nessa pesquisa. Neste sentido, a caixa-preta que se inicia a partir dos trabalhos de de Broglie, que consta nos livros textos escolares ou figura em trabalhos atuais, é a compreensão de que uma partícula material apresenta comportamentos de onda e matéria. A característica ondulatória de uma partícula pode ser discutida a partir da relação $\lambda=h / p=h / m v$ (na qual $\lambda$ é o comprimento de onda associado à partícula, $h$ a constante de Planck, $p$ o momento linear da partícula, $m$ sua massa e v sua velocidade). Essa relação pode ser obtida a partir da discussão apresentada por de Broglie em sua tese de doutorado (De Broglie, 1925), contudo não a encontraremos dessa forma em sua tese. Uma análise sobre como a equação anterior está implícita na tese de de Broglie pode ser encontrada em Brown e Martins (1984). 
terceiro ano. O terceiro motivo diz respeito à nacionalidade de de Broglie. Ele era um cientista francês trabalhando em um período em que a efervescência das produções em FM ocorria, sobretudo, em território germânico. Procuramos, então, trabalhar com um cientista cujos trabalhos se deram em um país que não era protagonista na área de FM. O quarto motivo, que se alinha ao terceiro, deveu-se ao fato de termos apresentado aos estudantes os conceitos de eletricidade e eletromagnetismo, também, a partir das publicações originais. No século XVIII e início do século XIX muitos trabalhos daquelas áreas foram publicados ou apresentados na França. Portanto, ao escolher um cientista francês do início do século XX para avaliar suas produções, poderíamos comparar as repercussões das publicações em um mesmo país, de cientistas de mesma nacionalidade, mas em períodos distintos.

A partir dessas considerações, a pesquisa aqui discutida e implementada em aulas de Física da educação básica teve por objetivo analisar quais questões sobre a validação do conhecimento científico emergem naquelas aulas, quando o estudo sobre as ciências têm por eixo condutor discussões sobre as publicações do conceito de dualidade ondapartícula de entidades materiais, proposto por de Broglie, entre o momento de sua construção inicial e seu estabelecimento como caixa-preta.

O referencial teórico-metodológico adotado levou-nos, ainda, a dividir a investigação em duas partes, uma bibliográfica e outra empírica, que se interconectaram durante o desenvolvimento da pesquisa. Para melhor expormos os resultados da investigação, dividimos este artigo em quatro seções. Na primeira, apresentamos um resumo dos aportes teóricos que guiaram a pesquisa. Em seguida, discutimos os delineamentos da investigação, apresentando tanto seu encaminhamento em sala de aula, quanto a análise documental que sustentou o trabalho. Na seção 3, discutimos a estrutura do curso em que a pesquisa ocorreu e na seção 4 discutimos os resultados da pesquisa. Fechamos o artigo com as considerações gerais a respeito do estudo.

\section{Encontrando os aportes teóricos}

A abordagem historiográfica da HCC nos levou a estudar o processo de construção das ciências deslocando o olhar do contexto sócio-histórico e dos cientistas cujos nomes permaneceram na história, para as práticas, representações científicas, cultura material ${ }^{2}$ e visual características de determinado tempo ou local da produção científica estudada (Pimentel, 2010). Como atividades humanas em que a cultura material se coloca como constituinte, as ciências se constroem numa rede heterogênea de atores humanos e nãohumanos. Com base nesse referencial historiográfico a análise do processo de construção do conceito de dualidade onda-partícula deve priorizar o estudo das práticas científicas e, assim, estudar como as redes de comunicação, as ideologias, a política, as artes e as

$2 \mathrm{O}$ estudo da cultura material parte da premissa de que os objetos feitos ou modificados pelo homem expõem as negociações e as crenças daqueles que os fizeram (Prown, 1982). Segundo Pimentel (2010), a nova história da ciência (ou a HCC) interessa-se pelos procedimentos e meios materiais utilizados no fazer científico pois entende que eles suportam as ideias, as práticas e as relações sociais que fazem parte da atividade científica. 
tecnologias se envolvem nas próprias práticas científicas e, portanto, na própria episteme do conceito.

Esse aporte historiográfico se aproxima da Filosofia e Sociologia das ciências de Bruno Latour. A proposta deste autor é a de que devemos observar a construção dos fatos científicos analisando todos os possíveis elementos que participam (ou participaram) daquela prática científica. Isto implica em considerar os agentes de diversas áreas (científica, social, cultural, política, religiosa, econômica, etc.) como atores de iguais relevâncias no fazer científico. De fato, para Latour (2011, 2013), não há distinção daquelas áreas. A dicotomia natureza e sociedade deve ser descartada, os produtos das ciências são constructos sociais e não uma descrição pura da natureza. Portanto, o conhecimento científico possui historicidade, possui localidade e temporalidade.

Para compreendermos a construção de um fato científico, então, devemos acompanhar os diálogos iniciais com pesquisadores da área estudada, através da leitura de artigos já publicados, perpassando pela obtenção de financiamentos, equipamentos e aliados, culminando na divulgação de resultados. Latour e Woolgar (1997) entendem o trabalho dos cientistas em um constante processo de ler e escrever artigos. A partir da escrita de seus resultados, os pesquisadores poderão conquistar novos apoiadores, obter recursos, receber críticas, possibilitar a utilização de seus produtos em áreas afins (na indústria, por exemplo), enfim, poderão ampliar uma rede capaz de sustentar a criação daquele conceito.

A Sociologia e Filosofia das ciências de Latour, então, nos impõe estudar a construção do conceito de dualidade onda-partícula de de Broglie considerando os diversos elementos que compõe a extensa rede na qual a construção do referido conceito se insere. E, assim, contemplar os agentes humanos e não-humanos (denominados por Latour de actantes) por ela responsáveis. Os actantes não possuem posições hierárquicas na rede, e, portanto, na construção do conceito encontramos uma relação simétrica entre atores humanos e não-humanos (Latour, 2001).

Latour (2011) defende que para estudarmos a ciência em formação, devemos considerar, além das relações simétricas entre os actantes, o estabelecimento daquilo que o autor denomina como uma caixa-preta nas ciências. Como destacamos na introdução, caixa-preta refere-se ao conceito científico já estabelecido, validado pela comunidade científica e, portanto, que se sustenta independente da descrição e ações da rede que originalmente o articulou ${ }^{3}$. A construção de uma caixa-preta é uma ação coletiva, na qual os diálogos entre os elementos deste processo geralmente se dão por meio da publicação de artigos em periódicos. Estas publicações, por sua vez, serão modificadas, sofrerão acréscimos ou reduções em seus conteúdos ao longo do processo de validação

\footnotetext{
3 O termo "caixa-preta", segundo Latour (1997), refere-se a um argumento defendido por Whitley (1972). Whitley apresenta em seu artigo uma proposta de uma Sociologia das ciências da "caixa translúcida", segundo a qual os processos do fazer científico devem ser considerados em suas análises, opondo-se àquilo que se definiu como "caixa-preta". Segundo o autor, sua Sociologia poderia avaliar "como diferentes conjuntos de ideias sobre o mundo natural - e como isso é definido em tempos e espaços diferentes — ocorrem e são avaliados" (Whitley, 1972, p. 63, tradução nossa)." (Whitley, 1972, p. 63, tradução nossa).
} 
do conceito estudado. Em outros termos, uma caixa-preta nas ciências seria a teoria ou conceito que, depois de muito discutido e trabalhado pelos pares, é dado como estabelecido, e, portanto, constitui-se numa "verdade científica", usada pelos cientistas sem que se faça necessário citar a obra na qual o conceito inicialmente foi apresentado (Lima et al., 2018).

Assim, no encontro dos dois aportes teóricos e considerando o episódio histórico tratado, concentramos atenção na prática das publicações científicas em que o conceito de dualidade de de Broglie é apresentado, discutido e validado. Dessa forma, nosso olhar concentrou-se nos periódicos em que de Broglie publicou originalmente seu trabalho e naqueles considerados pela comunidade científica, daquele contexto cultural, como veículos importantes de divulgação do conhecimento entre pares. Consideramos, então, como actantes do conceito de dualidade onda-partícula os artigos originais que apresentaram o conceito de dualidade pela primeira vez, os artigos que os citaram e os jornais em que esses artigos foram publicados. Estes actantes são simetricamente relevantes quando comparados a outros, como, por exemplo, os autores daqueles artigos e as personalidades que contribuíram com as publicações e suas repercussões.

\section{Delimitando a pesquisa}

\section{Caminhos para a pesquisa empírica}

No que se refere à pesquisa empírica, o aporte adotado foi o da pesquisa qualitativa e, em particular, a etnografia (Andre, 2005). A investigação foi desenvolvida por um professor que ministrava as aulas regulares da disciplina de Física na turma na qual a pesquisa ocorreu. Ele era professor efetivo da instituição há cinco anos.

Por conta do aporte etnográfico, a pesquisa se iniciou, efetivamente, no primeiro contato do professor com os estudantes, no início do ano letivo. Porém, para apresentar os resultados da pesquisa focaremos no relato dos acontecimentos dos meses de outubro e novembro daquele ano. O professor entrou naquele grupo enquanto um agente externo oito meses antes das aulas de FM, interagindo e construindo relações de reconhecimento. Isto o possibilitou construir um perfil da turma e dos estudantes individualmente, conduzindo tanto a preparação das aulas quanto a análise dos resultados. Dessa forma, o reconhecimento da turma se deu desde o início do ano letivo, mas desenvolvimento do projeto e seus possíveis efeitos sobre os estudantes ocorreram somente nos meses finais daquele período.

A etnografia, por definição, caracteriza-se pela imersão do pesquisador em determinada cultura, com o propósito de elencar e compreender comportamentos da sociedade que a compõe. Nessa pesquisa, entendemos cultura como uma rede de significados, na qual homens e mulheres se inserem, moldando-a da mesma forma que são por ela moldados (Geertz, 2008). A análise dessa rede é "uma ciência interpretativa, à procura de significado" (Geertz, 2008, p. 4). O pesquisador etnográfico insere-se nessa rede para não somente tentar entender o sentido atribuído à determinada prática da 
cultura estudada, mas também esforçar-se "no sentido de entender como os significados se manifestam e constituem um universo cultural particular" (Goellner at al., 2010, p. $384)$.

$\mathrm{Na}$ educação a etnografia ganha contornos próprios. Nesse sentido, nos filiamos nessa investigação a Andre (2005). Portanto, consideramos que nosso estudo se pauta na etnografia, sendo assim do "tipo etnográfico e não etnografia no seu sentido estrito" (Andre, 2005, p. 24). A autora lista uma série de características que definem a etnografia na educação: observação participante, intensa e longa interação entre pesquisador e pessoas, objetos e locais investigados, entrevista intensiva, análise de documentos e ênfase no processo em detrimento do produto ou resultados finais (Andre, 2005).

No caso de nossa pesquisa, além do fato da mesma se situar no campo da educação é importante considerar que o pesquisador, como professor regente, foi o próprio agente que encontrou os dados, a esse respeito André afirma:

O fato de ser uma pessoa o põe numa posição bem diferente de outros tipos de instrumentos, porque permite que ele responda ativamente às circunstâncias que o cercam, modificando técnicas e coleta, se necessário, revendo as questões que orientam a pesquisa, localizando novos sujeitos, revendo toda a metodologia ainda durante o desenrolar do trabalho. (Andre, 2005, p. 24, 25)

$\mathrm{Na}$ condição de professor da turma, o pesquisador possuía familiaridade não só com aqueles estudantes, mas também com o ambiente escolar, reconhecendo os trâmites daquele estabelecimento de ensino. Nessa instituição, a formação do ensino médio era dividida em disciplinas de formação geral e disciplinas técnicas. Essa estrutura gerava aos estudantes uma sobrecarga de disciplinas, dificultando-os a se concentrarem no objetivo da maioria daqueles discentes, a entrada em Universidades após conclusão do ensino médio.

O pesquisador, por meio da coordenação pedagógica da escola, obteve, antes do início do ano letivo, informações sobre aqueles estudantes: suas trajetórias acadêmicas, relações interpessoais, desempenho e comportamentos em aulas. Importante destacar que como membro de um grupo de pesquisa, o professor debateu junto aos demais pesquisadores todo planejamento do curso e as informações obtidas em relação à turma. Isso se deu tanto através dos demais profissionais da instituição como suas próprias impressões enquanto docente, sobretudo no que diz respeito às posições dos estudantes diante de questões relativas ao fazer científico. Para tanto, desde as primeiras aulas, o professor construiu um diário de campo, no qual destacou não apenas observações a respeito do interesse e desempenho dos estudantes na disciplina e suas relações interpessoais, mas também sobre as questões e discussões sobre ciência que surgiam em sala de aula.

As reuniões do grupo de pesquisa ocorreram semanalmente. Assim, foi possível discutir periodicamente o planejamento das aulas em que o conceito de dualidade seria trabalhado, tanto antes quanto durante o ano letivo, além das impressões do professor frente aos estudantes. Nos meses anteriores às aulas de FM, o planejamento do curso foi 
revisto e discutido com o grupo de pesquisa, adequando o processo da pesquisa em si e a estrutura do próprio curso. Este processo se manteve ainda durante as aulas de FM. Isso permitiu que a investigação ocorresse no movimento cíclico previsto pela pesquisa etnográfica (Andre, 2005).

Em síntese, considerando que a pesquisa etnográfica ocorreu desde o momento em que o professor iniciou o ano letivo, o professor e o grupo de pesquisa avaliaram os perfis dos estudantes e planejaram, em conjunto, as aulas. Esta análise deu-se tanto a partir de seus registros das aulas regulares, como através do registro de impressões dos demais professores, relatadas nas reuniões ao final dos bimestres, além dos apontamentos obtidos na seção pedagógica da instituição.

Nesse processo, construímos um olhar a respeito das motivações dos discentes em relação aos estudos de ciências, seus interesses, as participações em atividades em sala de aula e outras características que nos respaldaram na construção do curso e na análise dos resultados. As colaborações dos demais professores e da seção pedagógica, por exemplo, nos indicaram que muitos estudantes se expressavam pouco no decorrer das aulas. Isso conjugado ao objetivo da pesquisa nos motivou a planejar momentos de discussões, a partir de indagações a respeito de como os estudantes entendiam o processo de escrever artigos científicos ou de ter acesso aos textos produzidos por cientistas. Por outro lado, com a expectativa de somente uma parcela da turma participar efetivamente das discussões em sala, consideramos que as impressões obtidas das anotações do professor não contemplavam a opinião de todos os participantes.

A turma alvo dessa pesquisa era composta por 23 estudantes com idades variando entre 16 e 18 anos. Era uma turma predominantemente feminina, com 17 alunas e 6 alunos. A escola em questão, como referimos anteriormente, é uma escola técnica com muitos cursos cuja base se concentra nas disciplinas da chamada área de ciências exatas e com ênfase na aplicação de algoritmos característicos da matemática. Isso, de certa forma, acaba por fazer que o estudante, ao ingressar no terceiro ano do ensino médio e técnico, já tenha estudado diversos conteúdos da Matemática e da Física. A turma encontrada nessa pesquisa enquadrava-se nessa perspectiva. Contudo, isso não garantia que aqueles discentes apresentassem bom desempenho naquelas disciplinas. Sabia-se que somente uma parcela da turma sentia-se à vontade diante desses conteúdos. Outro ponto a destacar é que as características levantadas para a turma indicavam que parte daqueles estudantes solicitariam maior ênfase na resolução de exercícios com aplicação de algoritmos, objetivando a resolução dos problemas contidos no livro texto ou mesmo nos concursos vestibulares que fariam ao final daquela etapa. De fato, o professor observou este comportamento por parte da turma, o que o condicionou a planejar as aulas descritas neste trabalho considerando aquele objetivo.

O conteúdo previsto para aquele ano letivo, naquela disciplina, era Eletricidade, Eletromagnetismo, Física Moderna e Ondulatória. Dentre estes, os estudantes já haviam estudado alguns conceitos de Eletricidade e Magnetismo em anos anteriores nas disciplinas da área técnica, com ênfase na resolução de problemas práticos, 
negligenciando a compreensão daqueles conceitos e sem uma abordagem histórica, cultural ou sociológica.

Naquele ano, os alunos cursavam 20 disciplinas, totalizando 41 aulas de 50 minutos por semana. A disciplina de Física possuía duas aulas semanais. A instituição ainda promovia a participação dos discentes em programas de iniciação científica $\left(\right.$ PIBIC-EM ${ }^{4}$ ), em projetos de pesquisa ou extensão.

As aulas em que o conceito de dualidade onda-partícula de de Broglie foi trabalhado ocorreram em quatro encontros de 100 minutos (dois tempos de aulas conjugados), no intervalo de um mês.

\section{A consolidação da dualidade onda-partícula de de Broglie como uma caixa- preta da ciência}

Nessa seção, apresentamos resultados da pesquisa teórica. Uma investigação de cunho documental com intuito de analisar quais artigos originais apresentaram o conceito de dualidade onda-partícula de de Broglie e quais os referenciaram nos anos seguintes à publicação original.

A Figura 1 apresenta um quadro com os artigos de de Broglie e sua tese de doutorado $^{5}$ que apresentam seu conceito de dualidade onda-partícula ${ }^{6}$. Tomamos os periódicos em que de Broglie publicou seus artigos como referência para encontrarmos os artigos que citaram alguns de seus trabalhos originais. Selecionamos esses veículos, pois eles figuravam entre as principais revistas francesas, inglesas e alemãs, países de destaque nas publicações científicas nas primeiras décadas do século XX. Os periódicos analisados foram Comptes Rendus (França), Journal de Physique et le Radium (França), Nature Magazine (Inglaterra), Philosophical Magazine (Inglaterra) e Annalen der Physik (Alemanha).

Para encontrarmos os artigos que referenciavam os trabalhos de Louis de Broglie, buscamos o termo "de Broglie" nas palavras chaves, títulos, e corpos dos textos dos artigos publicados e disponibilizados nos sítios das próprias revistas ou em algum sítio repositório de obras científicas. Definimos o intervalo da pesquisa compreendido entre o ano de 1922, ano do primeiro trabalho publicado pelo cientista francês sobre o tema (Martins, Rosa, 2014), e o ano $2000^{7}$, último ano do século XX.

4 Programa Institucional de Bolsas de Iniciação Científica para o Ensino Médio (PIBIC- EM). Promovido pelo Conselho Nacional de Desenvolvimento Cientifico e Tecnológico (CNPq), oferecendo bolsas para alunos do ensino secundário, em um período de doze meses.

5 A tese de de Broglie foi apresentada e defendida em 1924 e republicada em 1925 na revista Annalen der Physik. Neste trabalho, utilizamos a versão publicada em 1925. (https://doi.org/10.1051/anphys/192510030022).

6 Martins e Rosa (2014) apontaram todos os artigos publicados por de Broglie, em diversos periódicos, e discutiram alguns destes documentos, além da tese de doutoramento do cientista. O sítio da Academia de Ciência Francesa também fornece a lista de publicações, notas e cartas de Luis de Broglie (https://www.academie-sciences. fr/pdf/dossiers/Broglie/Broglie_publi.htm). Os artigos estão disponíveis nos sítios dos periódicos ou em sítios repositórios.

7 Analisamos alguns artigos publicados após o ano 2000 para definirmos este recorte. Alguns trabalhos de de Broglie eram mais citados após aquele ano do que antes e, por isso, essas citações foram avaliadas em sua totalidade. Ambos os casos serão discutidos no decorrer deste trabalho. Ademais, para o objetivo de levantar a variação da frequência de citações de determinada publicação, o intervalo temporal pesquisado mostrou-se satisfatório. 
Figura 1. Quadro com artigos analisados de Louis de Broglie

\begin{tabular}{|l|l|l|l|}
\hline Ano & Título original do artigo & Periódico & País / Idioma \\
\hline 1922 & $\begin{array}{l}\text { Rayonnement noir et quanta de } \\
\text { lumière }\end{array}$ & $\begin{array}{l}\text { Journal de Physique et le Radium. } \\
3(11), 422-428\end{array}$ & França / francês \\
\hline 1922 & $\begin{array}{l}\text { Sur les interférences et la théorie } \\
\text { des quanta de lumière }\end{array}$ & Comptes Rendus 175, 811-813 & França / francês \\
\hline 1923 & Ondes et quanta & Comptes Rendus 177, 507-510 & França / francês \\
\hline 1923 & $\begin{array}{l}\text { Quanta de lumière, diffraction et } \\
\text { interférences }\end{array}$ & Comptes Rendus 177, 548-560 & França / francês \\
\hline 1923 & $\begin{array}{l}\text { Les quanta, la théorie cinétique } \\
\text { des gaz et le principe de Fermat }\end{array}$ & Comptes Rendus 177, 630-632 & França / francês \\
\hline 1923 & Waves and Quanta & Nature 112, 540 & Inglaterra / inglês \\
\hline 1924 & $\begin{array}{l}\text { A tentative theory of light } \\
\text { quanta }\end{array}$ & Philosophical Magazine 8 , 446-458 & Inglaterra / inglês \\
\hline 1925 & $\begin{array}{l}\text { Recherches sur la théorie des } \\
\text { quanta (tese) }\end{array}$ & Annalen der Physik, 22-128 & Alemanha / francês \\
\hline
\end{tabular}

A partir do material selecionado, separamos os documentos em dois grupos: os artigos cuja autoria era do próprio Louis de Broglie e aqueles de autores que citavam de Broglie ou no corpo do artigo ou nas referências. Em seguida, estudamos os artigos que citavam o conceito de dualidade onda-partícula proposta por de Broglie, analisando a natureza da citação, ou seja, se os autores debatiam a validade do conceito; se partiam das ideias de de Broglie, citando o autor ou sua obra, para construírem seus resultados; se utilizavam o conceito como uma referência histórica ou se o denominavam como uma grandeza ou algoritmo já estabelecido. Neste último caso, referimo-nos aos trabalhos que apresentavam apenas a nomenclatura da grandeza discutida por de Broglie, tal como "De Broglie Waveslength", "De Broglie Waves", " $\lambda_{\text {De-Broglie }}$ ou " $\lambda_{\mathrm{DB}}$ " sem fazer menção ao artigo original. Os documentos que não tratavam da dualidade-onda partícula, em nenhum dos casos citados anteriormente, foram eliminados.

Ressaltamos que não realizamos a leitura integral de todos os artigos selecionados na etapa anterior, tampouco contabilizamos os que acordavam ou discordavam com a proposta de de Broglie. Para o objetivo deste trabalho, bastou-nos verificar o quanto o conceito foi debatido após sua publicação seminal, verificar a natureza do texto e quantizar quantos autores citavam o conceito e em quais anos estas citações ocorreram.

Outro ponto que merece destaque refere-se àquilo que consideramos ser a caixapreta cuja construção se iniciou com de Broglie. Conforme alertamos na introdução, o conceito proposto pelo cientista que, após sofrer modificações (Brown \& Martins, 1984), ainda prevalece nos manuais didáticos, é o comportamento dual de entidades materiais (Cushing, 1994). Sobre o comportamento dual das radiações e a natureza dos fótons, entendemos que estes não foram conceitos inicialmente sugeridos por de Broglie, apesar de suas contribuições (Lima et al., 2020). Contudo, de Broglie não distinguia a

8 The London, Edinburgh, and Dublin Philosophical Magazine and Journal of Science. 
dualidade onda-partícula de um elétron ou da radiação luminosa (De Broglie, 1923a; Martins \& Rosa, 2014). Por essa razão, não excluímos de nossa análise os artigos que tratam exclusivamente do comportamento de fótons. Com base em Latour $(1997,2011)$, entendemos que estas publicações atuaram na construção da caixa-preta que estamos considerando e permitiram, ainda, a extensão da rede que sustentava aquele conceito.

Das revistas analisadas, as britânicas Nature Magazine e Philosophical Magazine são as que apresentam o maior número de artigos discutindo o conceito de dualidade apresentado por de Broglie. Os dois únicos artigos publicados por de Broglie em cada um daqueles periódicos ${ }^{9}$ (De Broglie, 1923d, 1924) são os trabalhos de sua autoria com os maiores números de citações. Foram 169 citações ao artigo da Nature e 124 citações ao trabalho da Philosophical Magazine, em diversos veículos ${ }^{10}$.

$\mathrm{O}$ artigo A tentative theory of light quanta, publicado na Philosophical Magazine em 1924 (De Broglie, 1924) abrange o conteúdo dos três artigos de 1923 publicados no periódico francês Comptes Rendus (De Broglie, 1923a; 1923b; 1923c) e, de forma mais densa, em sua tese de doutoramento (De Broglie, 1925) ${ }^{11}$. Localizamos 87 artigos que citam a dualidade onda-partícula de de Broglie no periódico alemão. Nota-se que essas citações não se referem a um único trabalho ou a trabalhos de um mesmo veículo e nem todas as citações concordam com as posições daquele autor.

Na Nature Magazine, o artigo publicado em outubro de 1923 e intitulado Waves and Quanta (De Broglie, 1923d), também resume as ideias defendidas por de Broglie nos artigos franceses Ondes et quanta (De Broglie, 1923a) e Quanta de lumière, diffraction et interférences (1923b). Contudo, o artigo da Nature Magazine não explora a nova dinâmica proposta por de Broglie. Trata-se de um artigo de meia página, no qual o autor sugere a possibilidade da associação entre a mecânica e a óptica. Nessa revista, encontramos 117 artigos que citam o conceito da dualidade onda-partícula, a partir dos trabalhos de de Broglie.

A única publicação de de Broglie, na revista alemã Annalen der Physik em 1925 foi a sua tese de doutorado (De Broglie, 1925). Esse artigo é referenciado 67 vezes nessa revista e 16 vezes em demais veículos.

\footnotetext{
9 Em 1958 a revista Nature publicou um segundo texto de Luis de Broglie (De Broglie, 1958) no qual ele apresentou o livro de David Bohm Causality and Chance in Modern Physics e traçou um breve panorama da Física naquele momento. Devido à natureza do texto, não o consideramos nesse estudo.

10 De acordo com a ferramenta crossref (https://www.crossref.org/). Os números apresentados neste artigo referem-se a consultas realizadas nos anos de 2017 e 2018, revisadas em janeiro de 2020. Além disso, só foram contabilizados os trabalhos que citam e/ou discutem o conceito dualidade onda-partícula.

$11 \mathrm{Na}$ tese de Broglie defendeu que a velocidade de uma partícula seria determinada por ondas-guia, onde cada partícula estaria associada a uma onda. Os trabalhos publicados na França em 1923 (De Broglie, 1923a, 1923b, 1923c) desenvolvem essa nova dinâmica, associando conceitos da óptica e da mecânica, a partir das equações de energias propostas por Einstein $\left(E=m c^{2}\right)$ e Planck $(E=h v)$. O segundo trabalho defende, também, a possibilidade de se observar o fenômeno de difração e interferência para partículas materiais (De Broglie, 1923b).
} 
De Broglie possui maior número de publicações e um maior número de citações (200 citações) em revistas francesas, em especial no periódico Journal de Physique et le Radium. Contudo, essas citações não referenciam um único trabalho ou trabalhos publicados naquele país, tampouco todos os trabalhos referenciam a proposta de dualidade que discutimos aqui.

Importante destacar que, com exceção do artigo La mécanique ondulatoire et la structure atomique de la matière et du rayonnement de 1927 (De Broglie, 1927), os artigos de de Broglie publicados em língua francesa, em periódicos franceses, sobre a dualidade onda-partícula, não possuem mais de dez citações cada, em veículos franceses e não franceses. $\mathrm{O}$ artigo La mécanique ondulatoire et la structure atomique de la matière et du rayonnement (1927) não aparece na Figura 1, pois foi publicado cinco anos após a primeira publicação de de Broglie sobre o tema, não configurando, portanto, como trabalho seminal sobre o conceito. $\mathrm{O}$ artigo recebeu, entretanto, 113 citações em diversos veículos, mas destas, somente nove são de trabalhos publicados até 1977. Setenta e uma dessas citações são de trabalhos publicados a partir de 2001, nas quais o conceito de dualidade e sua validade não são mais discutidos. Esses 71 artigos partem dos conceitos considerados validados para, por exemplo, iniciarem uma nova discussão na Mecânica Quântica (Büttiker \& Thomas, 1988).

Para discutirmos a frequência de citações dos artigos seminais de de Broglie, apresentaremos dois gráficos, os quais foram utilizados nas aulas que narraremos na próxima seção. Esses gráficos ilustram a distribuição temporal de artigos publicados nas revistas Nature Magazine (Figura 1) e Annalen der Physik (Figura 2) que citam a proposta de de Broglie. A escolha dessas revistas deveu-se ao fato de configurarem as que mais apresentam trabalhos citando o conceito de dualidade discutido pelo cientista. A análise das citações na Philosophical Magazine mostrou-se semelhante à análise das citações da Nature Magazine. Como já citado, ambas as revistas britânicas possuem grande número de trabalhos referenciando a proposta de de Broglie. Além disso, observamos que as frequências de citações em ambas apresentam características semelhantes. Dessa forma, optamos por apresentarmos aqui uma das duas revistas inglesas e outra de nacionalidade diferente. Almejamos, assim, explorar as citações em dois cenários distintos sem, contudo, expor um conteúdo muito extenso.

Ambos os gráficos nos mostram o grande número de citações nos anos próximos aos das publicações dos originais de de Broglie. Essa frequência diminui após algumas décadas, voltando, entretanto, a apresentar índices mais elevados em anos ou períodos posteriores. Ao analisarmos os gráficos a partir do conceito de caixa-preta de Latour, notamos que há discussões nas publicações iniciais sobre o conceito de onda-partícula e uma retração de discussões em seguida, indicando uma provável aceitação do conceito, ou mesmo uma rejeição. No caso específico deste trabalho, como lidamos com um conceito ainda presente nos livros didáticos de Física e como ponto de partida para novas discussões em artigos contemporâneos, entendemos a dualidade onda-partícula (de entidade materiais) de de Broglie como um conceito validado, uma caixa-preta. 
Figura 2. Gráfico com o número de trabalhos publicados na Nature Magazine que citaram a dualidade onda-partícula de Louis de Broglie

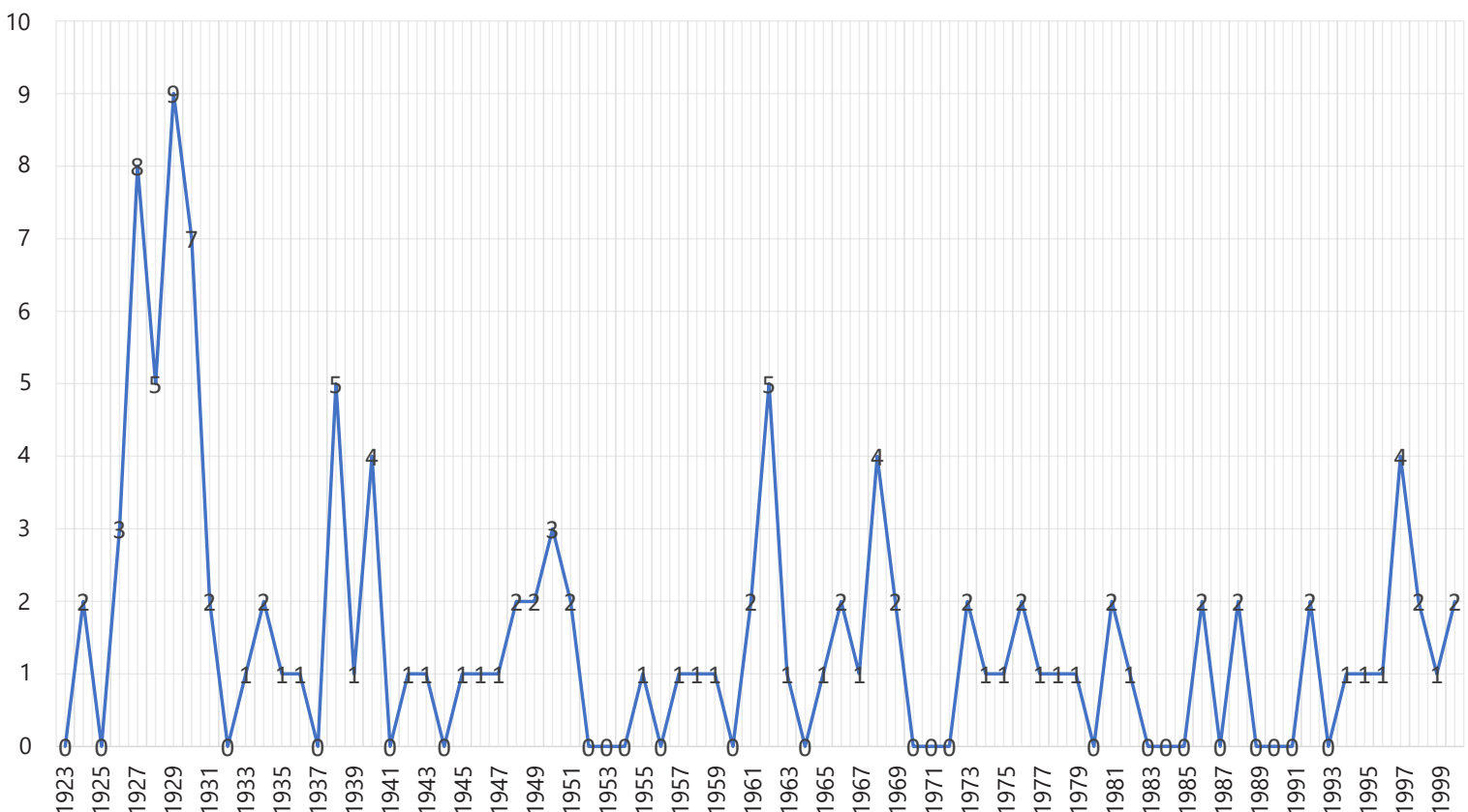

Figura 3. Gráfico com o número de trabalhos publicados na Annalen der Physik que citaram a dualidade onda-partícula de Louis de Broglie

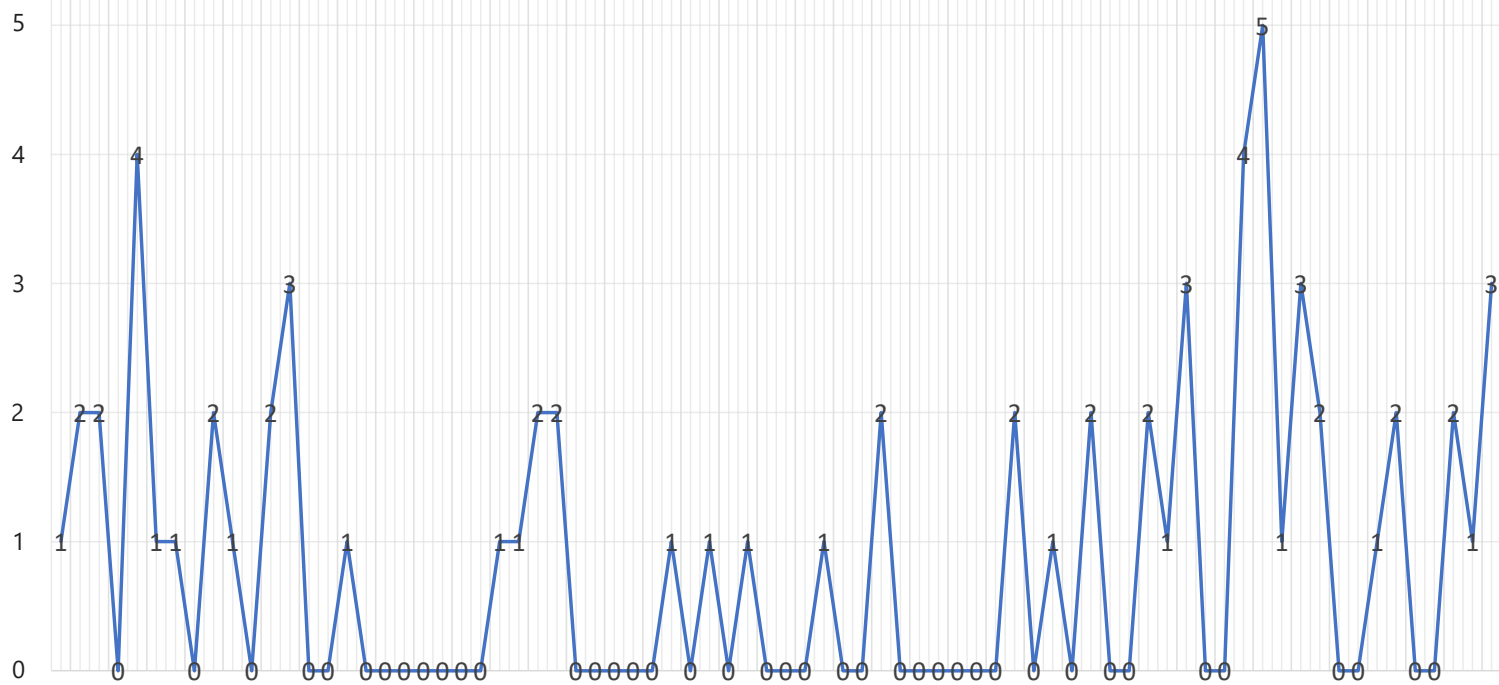

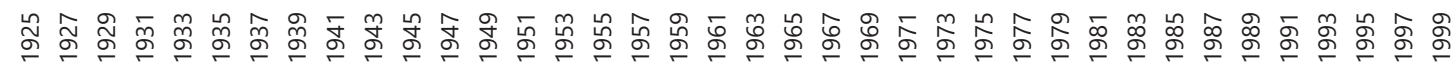

Por outro lado, o aumento das citações destacado nos gráficos, nas décadas finais do século XX (em especial na revista Annalen der Physik), levou-nos analisar a natureza 
destes artigos. A avaliação isolada dos números de citações poderia nos indicar uma revisão da caixa-preta validada em décadas anteriores. Notamos, entretanto, que estes artigos fazem referências às origens históricas da Mecânica Quântica, como no caso do trabalho Origin of quantum-mechanical complementarity probed by a 'which-way' experiment in an atom interferometer (Dürr et al., 1988). Em outros casos, utiliza-se do conceito nomeando-o com o nome daquele que o apresentou originalmente, como no artigo Front propagation in evanescent media (Büttiker \& Thomas, 1988) que utiliza a expressão “The de Broglie-wave length" (Büttiker \& Thomas, 1988, p. 10).

A análise realizada permite-nos traçar um pouco da rede que constitui a construção da caixa-preta da dualidade onda-partícula, a partir da interação dos actantes que selecionamos, ou seja, dos atores humanos (os autores dos artigos) e não-humanos (as revistas e os próprios artigos). Observamos as controvérsias em torno do novo conceito científico nos anos que sucedem sua publicação. A consolidação do conceito pode ser confirmada através das escassas referências feitas aos artigos fundadores entre as décadas de 1940 a 1970 e, ainda, no crescente número de citações nos anos finais do século XX. Isto porque nesses últimos anos os artigos partem do conceito para novas discussões ou o apresentam como marco histórico da Mecânica Quântica.

Outro resultado importante refere-se ao fato de que nas revistas francesas há um número grande de autores franceses que citam as obras de Broglie. Na revista alemã os autores também são, em grande número, de nacionalidade germânica. $\mathrm{Na}$ revista britânica, entretanto, os autores são de diferentes nacionalidades, italianos, dinamarqueses, alemães, além dos de países de língua inglesa. Este resultado nos permite concluir que a revista Nature Magazine, nas primeiras décadas do século XX, apresentava maior reverberação, quando comparada aos demais veículos citados neste trabalho. Possivelmente, essa característica da revista justifica a maior repercussão do trabalho de de Broglie naquele periódico.

Dentre os trabalhos que citaram a proposta de dualidade onda-partícula de de Broglie é possível localizar aqueles que foram amplamente referenciados. Isso demonstra a ampliação da rede na qual a discussão em torno ao conceito se estabelece, pois abrange mais periódicos e autores de localidades distintas. Da revista alemã podemos destacar o trabalho Über das Verhältnis der Heisenberg-Born-Jordanschen Quantenmechanik zu der meinem de Schrödinger (1926) que possui, atualmente, 239 citações. Na Nature Magazine o trabalho The Quantum Postulate and the Recent Development of Atomic Theory, de Niels Henrik David Bohr (1885-1962) (1928), possui 376 citações desde sua publicação até 2019. Apesar de procurarmos olhar para as práticas de publicação em detrimento dos grandes nomes das ciências, precisamos destacar que os autores em questão são actantes relevantes na disseminação das ideias de de Broglie. Bohr já havia publicado artigos de destaque, como os três artigos de 1913 nos quais propõe um modelo para o átomo (Bohr, 1913a, 1913b, 1913c), e Schrödinger possui, no mesmo volume de seu trabalho citado anteriormente, um artigo que foi citado 917 vezes.

Da análise dos artigos que citam os trabalhos seminais do conceito dualidade 
de de Broglie, podemos concluir que alguns fatores foram preponderantes para a sua dispersão. $\mathrm{O}$ veículo escolhido para a divulgação da nova proposta mostrou-se tão relevante quanto os próprios argumentos do autor. A tese de de Broglie continha sua proposta de dualidade onda-partícula, foi lida por autores cujos trabalhos, tinham grande repercussão à época e dialogavam com a proposta do francês ${ }^{12}$. Ademais, os artigos publicados na França, antes mesmo da defesa de sua tese, exploravam a proposta de de Broglie. Ao menos quatro publicações discutiam seu conceito, todas escritas em francês e publicadas em revistas francesas. Contudo, de Broglie republicou a tese integralmente na Alemanha e, seguindo orientações de Einstein, um dos avaliadores de sua tese de doutoramento (Martins \& Rosa, 2014), divulgou em revistas inglesas artigos que resumiam suas ideias.

Os caminhos seguidos por de Broglie para apresentar aos pares o conceito de dualidade ilustram como a validação do conhecimento científico perpassou por discussões que se deram, sobretudo, em veículos estrangeiros ao autor da proposta e, em ao menos, um idioma diferente àquele da tese de doutorado. $\mathrm{O}$ fato de o conceito ter sido publicado ainda em fase de discussão em idiomas de países expoentes na ciência da época foi fundamental para aquele conceito estabelecer uma rede capaz de torná-lo uma caixa-preta. Em outros termos, a mera apresentação e defesa de um conceito científico, mesmo que este venha a ser bem fundamentado e notado por pesquisadores de prestígio na área, precisou de reproduções em veículos de maior capilaridade na época. De tal forma que podemos afirmar que escolher em qual periódico será publicado o resultado de qualquer estudo configura uma prática importante do fazer científico.

\section{Relatos da pesquisa empírica}

\section{Uma narrativa sobre as aulas de dualidade onda-partícula a partir do percurso do ano letivo}

A partir da perspectiva da HCC e do olhar da Sociologia e Filosofia de Bruno Latour sobre o fazer científico, preparamos as aulas em que o conceito de dualidade onda-partícula foi discutido. Nessa etapa, nos concentramos na prática das publicações científicas dos cientistas, ou seja, nos resultados da análise documental apresentado na subseção 2.2.

Apesar de prevermos desenvolver o trabalho sobre dualidade e a pesquisa em si somente ao final do ano letivo, decidimos por iniciar as observações sobre o comportamento, as ponderações e as impressões dos estudantes desde os primeiros encontros do professor com a turma. Dessa forma, planejamos uma atividade para a primeira aula do ano letivo em que os discentes escreveram um texto a partir do seguinte enunciado: "Cite quais fatores você considera que são relevantes para que determinado conceito, lei ou teoria seja considerado verdadeiro, que seja aceito pelos demais cientistas."

12 Referimo-nos às leituras seguidas das opiniões de personalidades como Albert Einstein e Erwin Schrödinger (Martins \& Rosa, 2014). 
A atividade proposta não foi, inicialmente, conduzida com seriedade pelos estudantes. Eles alegaram que, por se tratar de uma aula de Física, não entendiam porque deveriam produzir um texto. O professor buscou explicar-lhes o objetivo daquela atividade, destacando ser importante ele conhecer o que os estudantes pensavam sobre o assunto para organizar suas aulas, ressaltando que escrever fazia parte das práticas dos e das cientistas e que por isso planejava repetir a atividade de escrita em outros momentos do curso. Essa posição dos discentes nos auxiliou a repensar as demais atividades durante o ano letivo. De tal modo que produzimos diferentes momentos no curso com vistas a possibilitar aos estudantes estudar Física através de atividades que não versassem apenas sobre aplicação de algoritmos.

A análise dos textos produzidos pelos discentes reforça resultados de pesquisas anteriores a respeito das concepções de estudantes sobre o fazer científico (Acevedo et al., 2005; Peron et al., 2011; Peron, 2014; Peron \& Guerra, 2017). Todos os textos destacaram que o conhecimento científico representa a natureza desvelada e descoberta por cientistas. Fora isso, defenderam que o conhecimento científico é e foi alcançado a partir de experimentos e provas matemáticas e que seus resultados, quando seguem critérios metodológicos corretos, são irrefutáveis. Alguns textos apontaram, ainda, o controle da Igreja sobre a produção e a divulgação do saber científico, antes do período renascentista, contrapondo essa situação aos dias atuais, que entendem ser de maior liberdade para as ciências. Nove estudantes afirmaram que na atualidade há liberdade para se publicar qualquer resultado, desde que obtido seguindo padrões do fazer científico. Quatro textos, contudo, relatavam que atualmente algumas pesquisas tinham controle financeiro, seja por parte do Estado, seja por financiadores privados. Assim, os únicos elementos considerados extra científicos ${ }^{13}$ indicados em poucos textos diziam respeito aos limites sobre o fazer científico, ora definido pela Igreja ora pelo financiamento das pesquisas.

Os resultados anteriores e o reconhecimento de que nos dois primeiros anos do EM esse grupo de estudantes não tivera contato com abordagens históricas ou discussões sobre a ciência nos fizeram decidir trabalhar todo o conteúdo de Física do terceiro ano a partir de uma perspectiva histórica. Para tal, consideramos a prática científica da divulgação científica entre pares o elemento central de discussão.

Dessa forma, ao apresentar um conceito científico, o professor destacava a obra seminal em que o conceito era apresentado, ressaltando o veículo de publicação (cartas, livros ou artigos), o ano, o idioma do texto publicado, além da nacionalidade do(s) autor(es) e a repercussão do trabalho apresentado. De acordo com o material selecionado, expúnhamos o frontispício do material, ou as imagens que auxiliavam no entendimento do conceito e, em alguns casos, as equações presentes naqueles documentos. Importante destacar que as equações e textos dos artigos, quando expostos, foram depois discutidos

13 Concordamos com as considerações de Latour (2001, 2012, 2013) a respeito da inseparabilidade entre ciência e sociedade, de tal forma que, a rigor, não nos caberia definir elementos extra científicos ou intrínsecos ao fazer científico. Contudo, utilizaremos a expressão ao referimo-nos aos elementos que não são considerados, costumeiramente, como componentes do fazer científico. 
de forma adequá-los ao nível escolar dos estudantes.

Para exemplificarmos essa prática, tomemos o estudo introdutório ao Magnetismo, quando apresentamos o livro De Magnete (Gilbert, 1893). Ao apresentarmos a obra, destacamos a nacionalidade do autor, o idioma e o país de publicação do livro, discutindo o papel geopolítico da Inglaterra e como a ciência daquele país figurava no cenário científico, político e econômico europeu. Apresentamos imagens científicas contidas no livro nas quais o autor se apoiava para discutir o conceito de polaridade magnética ou a propriedade diretiva de agulhas imantadas. Após o estudo dos conceitos, discutimos como se deu a repercussão da obra, apresentando outros textos ou autores que utilizavam os conceitos presentes em De Magnete ou faziam referência direta à obra.

Registros do diário de campo apontam que, nas aulas do início do ano letivo em que as obras seminais eram apresentadas, expondo elementos que ultrapassavam a mera exposição de conceitos científicos, os estudantes manifestavam desinteresse. Muitos estudantes somente anotavam em seus cadernos as equações apresentadas ou, em alguns casos, só destinavam atenção ao professor durante a resolução de exercícios do livro didático. Os registros do diário de campo indicam, entretanto, que este comportamento se alterou no decorrer do ano. As alunas e os alunos habituaram-se com a forma de o professor trabalhar o conteúdo. Como as avaliações promovidas pelo professor apontavam questões conceituais e questões sobre as práticas científicas, entendemos que aqueles estudantes, que eram muito ligados aos resultados das avaliações formais por entender que o bom desempenho garantiria uma vaga em uma Universidade pública, aos poucos foram percebendo que aquelas aulas faziam parte do curso de Física. Nos últimos meses do ano, o professor já observava um comprometimento maior dos estudantes nas aulas centradas em elementos históricos.

Apesar do desinteresse registrado, durante as primeiras aulas do ano letivo em que as obras originais estudadas eram apresentadas, alguns estudantes colocaram, nesses encontros, perguntas a respeito de como um cientista conhecia a obra de outros pesquisadores. Questionaram, por exemplo, como os cientistas reconheciam que era importante ler uma determinada obra científica. A partir desses questionamentos, planejamos uma aula em que foram trazidas questões para problematizar como o conhecimento científico foi propagado entre os pares no decorrer da história ocidental.

Iniciamos a referida aula apresentando questões de forma a incentivar os estudantes a se manifestarem a respeito de como achavam que ocorria a publicação de resultados de uma pesquisa científica nos dias atuais. Antes de qualquer estudante se manifestar, uma aluna que integrara projetos de pesquisa coordenados por professores da instituição, tendo já participado na produção de artigos científicos e de congressos científicos, falou sobre sua experiência. Sem solicitação do professor, ela descreveu o processo de busca por um veículo propício para a publicação do trabalho do grupo de pesquisa em que estava inserida, as dificuldades da escrita, além de compartilhar com os demais alunos as controvérsias acadêmicas que presenciou no congresso que participou. Apesar da contribuição daquela aluna, os demais estudantes que se pronunciaram reafirmaram 
o que haviam descrito no texto do início do ano letivo, que publicar determinado conhecimento científico era simples, desde que se seguisse os trâmites da ciência e se apresentasse provas. Não houve nenhum relato sobre avaliação de trabalhos por pares ou possíveis interesses na publicação de um resultado específico. Os estudantes, também, não relataram sobre a dificuldade de se publicar em determinado periódico nem mesmo a questão do idioma foi mencionado. A aluna bolsista, citada anteriormente, nada acrescentou naquele momento sobre a avaliação dos pares ou qualquer outro trâmite após a submissão do trabalho, conteve-se em reafirmar a dificuldade da adequação do texto para a publicação.

Indagamos aos estudantes sobre o acesso aos artigos científicos, se eles sabiam como fazê-lo, ou seja, quais caminhos eles deveriam seguir e quais obstáculos encontrariam para ter acesso às publicações científicas atuais. Neste caso, os discentes destacaram que o conhecimento científico estava nos livros ou em artigos na internet e que todos poderiam acessá-los caso o quisessem, sem que houvesse qualquer impedimento. A aluna que participara do projeto não fez qualquer comentário nesse momento.

Essas impressões dos estudantes foram consideradas e, assim, prosseguimos apresentando os diversos tipos de publicações científicas no decorrer da história, tanto as escritas como as orais, desde pergaminhos e livros até apresentações em teatros de anatomia e gabinetes. Discutimos como a imprensa e a organização de uma rede de correspondências (República das Cartas) compuseram a cultura e a prática científica no século XVIII (Jardim \& Guerra, 2017). Debatemos quando e onde as academias científicas estabeleceram-se como importantes divulgadoras do saber científico, destacando como as publicações periódicas daquelas academias se deram e a importância das mesmas para a divulgação entre pares do conhecimento produzido (Hagstrom, 1975; Hin \& Subramaniam, 2009).

Quando do início dos estudos de FM, retomamos os principais pontos daquela aula sobre publicações, ressaltando que no século XX o número de periódicos e de artigos publicados aumentaram consideravelmente em relação, aos séculos XVIII e XIX. Mencionamos que este crescimento foi acompanhado de novas práticas de validação por pares. Alguns veículos, por exemplo, passaram a publicar trabalhos após a análise de pelo menos dois árbitros, que deveriam ser cientistas de renome na área debatida no artigo. Prática esta que contrastava com a forma em que os textos eram selecionados pelas Academias científicas no século XVIII ou início do século XIX (Hin \& Subramaniam, 2009).

Nesse momento, recordamos a fala da aluna bolsista e questionamos se ela sabia o porquê de a escrita de seu artigo ter seguido o padrão específico do periódico que seu grupo almejava publicar. A aluna respondeu que se não escrevessem de uma forma que agradasse os avaliadores o trabalho não seria aceito e sua orientadora queria que a publicação ocorresse naquele periódico. O professor, então, ressaltou que o conteúdo científico do artigo não era o único objeto de análise pelos pares, de tal sorte que a não adequação do texto àquele veículo poderia ocasionar em sua rejeição, ou seja, os 
resultados dos trabalhos daquele grupo de pesquisa poderiam não ser divulgado em um periódico considerado pelo grupo de grande capilaridade.

Prosseguimos explorando, a partir do que os estudantes conheciam das aulas de história, a situação econômica e política da Europa no início do século XX, mais precisamente nas décadas de 1910, 1920 e 1930, e de países expoentes no fazer científico à época (Alemanha, Japão e Estados Unidos). Discutimos como alguns países, como a França, diminuíram sua influência sobre outras nações, tanto politicamente quanto nas ciências (Hobsbawm, 1994). E como Alemanha e Estados Unidos investiram na área científica no período entre guerras. Ressaltando que muitos países aumentaram ou mantiveram seus investimentos na área (caso do Reino Unido), mas atentamo-nos aos Estados Unidos e Alemanha devido ao destacado crescimento de suas produções científicas no período.

A participação dos estudantes no decorrer dessas aulas, em que o professor solicitava suas contribuições para recordar os elementos históricos, foi maior do que esperávamos. Sabíamos que aqueles discentes eram mais reservados e que pouco participavam das aulas. Além disso, estávamos em um período muito próximo aos exames vestibulares e às provas finais da própria instituição, de tal forma que todos os alunos almejavam, declaradamente, aprender a lidar com os algoritmos da Física aplicando-os em resolução de problemas, que julgavam cruciais para as provas e exames. Apesar disso, não houve mudança de interesse dos estudantes naquelas aulas. Além do fato de que alguns apontamentos dessas aulas surgiram em participações de estudantes em ocasiões posteriores, como veremos na próxima seção.

Em seguida, mas antes de trabalharmos com o conceito dualidade ondapartícula, exploramos outros assuntos do currículo de FM, como efeito fotoelétrico, teoria da Relatividade Restrita, equação de Planck e quantização de energia e o modelo atômico de Bohr, também, a partir das publicações que apresentaram tais conceitos à comunidade científica, explorando alguns dos trabalhos que os referenciam, de forma semelhante às aulas de magnetismo.

A análise da prática das publicações para pares foi aprofundada no momento em que abordamos o conceito de dualidade onda-partícula. Neste caso, partimos dos trabalhos do francês Louis de Broglie sobre aquele tema, publicados no início da década de 1920. Analisamos os jornais em que os mesmos foram publicados e as referências encontradas em tais publicações. Discutimos o perfil e capilaridade das revistas, nas quais os trabalhos foram publicados (quais países, idiomas e processo de seleção de artigos nelas publicados). Em paralelo, introduzimos e interpretamos a equação que define o chamado comprimento de onda de de Broglie.

Utilizamos, então, os resultados obtidos na pesquisa documental tratada na seção 2.2, para discutirmos o número de publicações que citam os trabalhos de de Broglie entre os anos de 1922 e 2000, a partir dos gráficos das Figuras 2 e 3. Analisamos junto aos discentes as revistas inglesas Nature Magazine, a alemã Annalen der Physik, discutindo o conteúdo de cada artigo, ressaltando que eles reproduziam aquilo que o 
autor defendera em sua tese de doutorado. Discutimos, ainda, as citações nas principais revistas francesas, enfatizando que se tratavam de poucas menções dos trabalhos de de Broglie publicados na França. Contabilizamos, então, quantas citações aos trabalhos de de Broglie sobre dualidade onda-partícula apareceram nesse período em periódicos da Alemanha e Inglaterra, a partir dos gráficos das Figuras 2 e 3.

As revistas britânica e germânica são as que apresentam o maior número de citações que concordam com a proposta de de Broglie, além de apresentarem os trabalhos do francês que receberam maior atenção da comunidade científica. Neste momento, recordamos aulas anteriores, destacando o papel econômico e científico da Alemanha e Inglaterra. Destacamos que em ambas as revistas se observa um número significativo de trabalhos que discutem a teoria do francês nos dez anos seguintes às suas publicações e uma queda deste número nos anos seguintes e que as citações após duas ou três décadas já não debatem a teoria. Discutimos que algumas publicações se posicionavam a favor e outras contra à proposta de dualidade de de Broglie e listamos as frequências de citações referentes ao seu trabalho, mostrando como elas diminuem gradualmente, mas sem que o conceito deixe de ser utilizado.

Um ponto que demos atenção durante essa discussão, que desvia da proposta de se apegar somente às publicações científicas, foi a relação pessoal entre de Broglie e Albert Einstein. Einstein já havia publicado sua definição de dualidade onda-partícula para luz quando de Broglie defendeu sua tese de doutoramento (Martins, \& Rosa, 2014) e, apesar de a proposta do francês diferir da sua, ele compartilhava do interesse em divulgar essa nova abordagem (Martins \& Rosa, 2014). Martins e Rosa (2014) relatam que Einstein teria contribuído com a divulgação das ideias de de Broglie, inclusive citando a tese do francês em um artigo publicado em 1925.

Destacamos ainda que outros trabalhos apresentaram propostas semelhantes às de de Broglie em anos anteriores (Mehra \& Rechenberg, 1982). Um destes foi publicado 1907 na revista alemã Physikalische Zeitschrift intitulado Elementarquantum der Energie, Modell der negativen und positiven Elektrizität (Stark, 1907). De Broglie não citou este artigo em seus trabalhos, tampouco Johannes Stark (1874-1957) figura entre aqueles que referenciam os artigos de de Broglie nas revistas e anos avaliados neste trabalho. Outro artigo que também utiliza o conceito de dualidade onda-partícula de de Broglie e que foi mencionado em sala de aula é o artigo de 1926 de Scröringer intitulado An undulatory theory of the mechanics of atoms and molecules da revista norte americana Physical Review (Schrödinger, 1926). Este é o terceiro artigo publicado por Schrödinger apresentando sua mecânica ondulatória, o primeiro publicado fora da Alemanha, em inglês, é o seu segundo artigo a citar os trabalhos de de Broglie. Esse é um de seus trabalhos de maior impacto na teoria quântica (Schmidit, 2008). 


\section{Discutindo resultados}

Relatamos que os discentes apresentaram uma mudança em relação à seriedade com a qual eles encaravam as aulas com abordagem histórica. Com o decorrer dos encontros, eles passaram a dedicar maior atenção àqueles conteúdos e a realizarem mais anotações. Mas, não foram percebidas alterações na interação de grupos específicos de estudantes durante as aulas ao longo de quase todo o ano letivo. Ou seja, aqueles com maior participação durante os encontros iniciais assim o mantiveram. Como mencionado anteriormente, essa característica manteve-se, inclusive, no decorrer das apresentações em que discutíamos os aspectos econômicos, culturais e científicos da Europa nas primeiras décadas do século XX. A exceção notada em relação à postura dos estudantes deu-se nas últimas aulas de FM, quando notamos maior participação de alguns estudantes, que ao longo do ano não participaram ativamente das demais aulas. Estes alunos, no período que correspondia ao final do ano letivo, necessitavam de bom rendimento na disciplina para que obtivessem média suficiente para a aprovação. Fato este que nos impede de diagnosticar se o maior empenho reflete o interesse pela temática de FM ou a necessidade de grau para aprovação na disciplina.

Do diário de campo, notamos que durante as aulas em que foram apresentados os gráficos das citações de de Broglie (Figuras 2 e 3), os estudantes, ao final, apontaram que um único artigo não garante a validação de determinado saber científico (alegando que o próprio de Broglie precisou revisitar sua teoria). Comentários dos estudantes em relação à afirmação de um aluno, de que o maior número de citações próximas às primeiras publicações constitui a discussão em torno daquele saber e que a queda do número de citações representa que "conceito se torna senso comum", indicam que os mesmos corroboraram a conclusão desse estudante.

Durante as aulas de dualidade onda-partícula de de Broglie, percebemos que os estudantes referenciavam os cientistas apresentados a eles como os grandes nomes da ciência, indicando que a ideia do cientista isolado não foi problematizada. Não almejamos, especificamente, desconfigurar a crença dos estudantes no trabalho isolado dos cientistas. Esperávamos, porém, que os debates em torno às publicações das obras seminais em todo ano letivo levariam a problematizações dessa crença. Por outro lado, nas discussões em torno as citações de Einstein e Schrödinger ao conceito de dualidade, alguns estudantes apontaram essas citações como fatores decisivos na validação do conceito de de Broglie. Contudo, estes destaques apareceram apenas nesses momentos do curso.

Importante destacar que duas semanas após o término das discussões sobre dualidade, em uma aula destinada à resolução de problemas do livro didático, o professor questionou aos estudantes quais os possíveis fatores que conduzem à validação de determinado conceito científico. Nesse momento, alguns estudantes citaram as ações e escolhas dos cientistas a respeito do idioma, do local e da forma de escrever do artigo que divulga seus trabalhos, como práticas relevantes para a construção e validação daquele conceito. Comparando as citações dos trabalhos de de Broglie na França e na Inglaterra, 
uma aluna justificou: “[...] Broglie publicou os seus (trabalhos) em uma época onde a França não estava tão importante culturalmente, mas é onde (sic) a língua inglesa se tornou praticamente universal no mundo da ciência." (Aluna 2).

Nosso referencial teórico-metodológico levou-nos a considerar que os atores humanos têm a mesma importância que os demais elementos não-humanos. Assim, o fato de os cientistas como Einstein e Schrödinger não reaparecerem nas considerações das alunas e dos alunos em apontamentos, como os destacados da Aluna 2, indica que a atuação de agentes não-humanos na rede, a qual sustenta o conceito de dualidade, foi considerado pelos estudantes.

Ainda em relação ao questionamento do professor, alguns estudantes destacaram que de Broglie republicou sua tese na Alemanha e a síntese de seus artigos franceses em dois artigos em inglês, na Inglaterra, em virtude da relevância que ambos os países tinham naquele contexto, tanto nos aspectos políticos quanto econômicos. Durante o debate, recordamos os trabalhos de Ampère, discutidos nas aulas de Eletromagnetismo, os quais foram originalmente publicados em francês, na França, e tiveram muitas citações, não só na França, mas em outros países europeus. Nesse momento um aluno interveio: "[...] de Broglie nasceu em uma época diferente, na época das guerras. Ele percebeu o crescimento da Alemanha e a globalização da língua inglesa de lá pra cá [...]”. (Aluno 3).

A validação do saber científico, ou a definição de uma caixa-preta nas ciências, também foi destacada por alguns estudantes. Isso se deu quando os mesmos relataram a diminuição do número de citações observada nos gráficos apresentados em aula, como exemplo destacamos: "Com o passar dos anos os conteúdos dos artigos são divulgados e começam a fazer parte do senso comum. Não precisa mais fazer as citações dos trabalhos de antes". (Aluno 3); "O número de citações mostra como os artigos e as ideias eram difundidas na época, qual era a informação mais aceita [...]”. (Aluno 4).

Importante ressaltar que encontramos entre os estudantes aqueles que não apresentaram elementos considerados extra científicos para justificar a validação de determinado saber. $\mathrm{Ou}$, ainda, aqueles que não mencionaram as citações como preponderantes para se compreender o papel da avaliação dos pares nas práticas científicas e a validação ou rejeição de determinado conhecimento científico. Contudo, se voltarmos ao objetivo deste trabalho, concluímos que ao apresentar os conceitos científicos a partir das práticas de publicação de obras científicas foi possível potencializar com aquele grupo de estudantes, que não tivera contato nos dois primeiros anos do EM com discussões sobre as ciência, espaços capazes de promover reflexões que apontaram para a compreensão da ciência como construção social, na qual diversos actantes participam de sua validação. 


\section{Conclusões e Implicações}

A pesquisa aqui apresentada teve por objetivo discutir que questões sobre as ciências em formação emergem em aulas de Física quando se privilegia discussões sobre a prática científica de divulgação entre pares. A delimitação do referencial teóricometodológico nos fez focar nos parâmetros sobre esta prática indicados pelo exame das publicações de um conceito entre sua construção inicial e seu estabelecimento como caixa-preta.

Do estudo teórico foi possível destacar que fatores como quando e onde se deram as publicações estudadas, quem as incentivou ou as apoiou e como se escreveu o artigo são elementos tão importantes quanto o quem ou que se defende. O fato de artigos publicados antes de 1922, de outros autores, que defenderam posições parecidas a de de Broglie não figurarem como importantes trabalhos na história da Física, corrobora o que estamos defendendo.

Os resultados da pesquisa empírica indicam que, ao longo das aulas em que os gráficos ilustrativos do comportamento das citações dos trabalhos seminais de de Broglie e na aula após as discussões de FM, os estudantes problematizaram suas visões iniciais a respeito do processo de validação da ciência. Nessas aulas, eles consideraram, ao contrário do início do ano letivo, agentes não-humanos como a forma, o idioma, o veículo em que um artigo científico é divulgado, assim como suas citações, como fatores cruciais para a validação de um conceito. Dessa forma, esses resultados indicam caminhos para problematizar visões de ciências que apontam que provas matemáticas e experimentais são os únicos caminhos para validar o conhecimento científico.

Os resultados apontam, ainda, que naquelas aulas os alunos reconheceram que para a validação do conceito de dualidade de de Broglie foi fundamental que a tese de doutorado que apresentava o conceito saísse da França e fosse publicada na Alemanha e, também, em língua inglesa. Nessas aulas, os estudantes ainda apontaram que a ampla divulgação entre pares daquele conceito e, portanto, sua discussão permitiu que o mesmo fosse estabelecido como uma caixa-preta (Latour, 2001). Dessa forma, esses resultados reforçam outros da literatura que apontam que o estudo das ciências em formação permite aos estudantes compreenderem como as relações de poder na sociedade também se manifestam e se consolidam nas ciências (Santos \& Meneses, 2010).

Uma questão importante a ser destacada é que a turma em que o trabalho ocorreu era majoritariamente feminina e que todos os agentes humanos apresentados eram homens. Isso, aliado ao fato de uma das alunas estar num grupo de pesquisa, levou-nos a considerar que questões relativas à participação feminina na ciência poderiam surgir naquelas aulas. Porém isso não ocorreu. Esses resultados, de certa forma, reforçam outros da literatura que apontam para a importância de trazermos às salas discussões explícitas sobre a ciência (Lederman, 2007). Assim, nossos resultados sugerem que para potencializar discussões sobre participação de mulheres na ciência deveríamos levantar questões que explicitamente tratassem da temática.

Consideramos que o estudo narrado aponta para a possibilidade de se trabalhar 
em sala de aula como determinado conceito científico se estabiliza a partir das práticas de publicação daquele saber entre pares e, assim, problematizar visões que apontam que a validação do conhecimento se dá separado da sociedade.

O estudo da construção do conceito de dualidade onda-partícula, considerando tudo o que foi exposto no decorrer deste trabalho, nos permitiu vislumbrar como atores variados contribuíram para a formação de uma rede que sustenta aquele constructo. Dessa forma, podemos afirmar que os actantes que constroem cada conceito ou teoria nas ciências são distintos, ou seja, cada processo é único. Entendemos que debater essa não normatização do fazer científico, na educação básica, permite-nos destacar elementos, que até então eram considerados somente culturais ou sociais, como integrantes das próprias ciências. Essa forma de se analisar o fazer científico, de acordo com a Sociologia e Filosofia de Bruno Latour, possibilita-nos, ainda, localizar actantes que se tornaram invisíveis na História das Ciências. Podemos observar os interesses políticos, econômicos ou pessoais, localizar pessoas que foram negligenciadas nas narrativas anteriores, entre outros fatores característicos de cada episódio.

\section{Referências}

Acevedo, J. A., Vázquez, A., Paixão, M. F., Acevedo, P., Oliva J. M., \& Manassero, M. A. (2005). Mitos da didática das ciências acerca dos motivos para incluir a natureza da ciência no ensino de ciências. Ciência \& Educação, 11(1), 1-15. https://doi.org/10.1590/ S1516-73132005000100001

Acevedo-Diaz, J. A. (2009). Enfoques Explícitos versus implícitos en la enseñanza de la naturaleza de la ciencia. Revista Eureka sobre Enseñanza y Divulgación de las Ciencias, 6(3), 355-386.

Allchin, D (2013). Teaching the nature of Science - Perspectives and resources. SHiPS Education Press.

Allchin, D. (2011). Evaluating knowledge of the nature of (whole) science. Science Education, 95(3), 518-542.

Andre, M. D. E. A. (2005). Etnografia da prática escolar. Papirus Editora.

Auler, D. (2007). Enfoque ciência-tecnologia-sociedade: Pressupostos para o contexto Brasileiro. Ciência \& Ensino, 1(número especial), 1-20.

Barros, A. A., \& Barros, M. A. (2018). "Uma teoria experimental dos quanta de luz" de Louis de Broglie: Uma tradução comentada. Revista Sustinere, 6, 175-200. https://doi. org/10.12957/sustinere.2018.31732

Bohr, N. (1913). On the Constitution of Atoms and Molecules, Part I. Philosophical Magazine, 26, 1-24. http://doi.org/10.1080/14786441308634955

Bohr, N. (1913). On the Constitution of Atoms and Molecules, Part II Systems Containing Only a Single Nucleus. Philosophical Magazine, 26, 476-502. http://doi. org/10.1080/14786441308634993 
Bohr, N. (1913). On the Constitution of Atoms and Molecules, Part III Systems Containing several nuclei. Philosophical Magazine, 26, 857-875. http://doi. org/10.1080/14786441308635031

Brown, H. R., \& Martins, R. A. (1984). De Broglie's relativistic phase waves and waves groups. American Journal of Physics, 52(12), 1130-1140. https://doi.org/10.1119/1.13743 Burke, P. (2008). O que é história cultural? Zahar.

Büttiker, M., \& Thomas, H. (1988). Front propagation in evanescent media. Superlattices and Microstructures, 23(3,4), 781-794. https://doi.org/10.1006/spmi.1997.0540

Cushing, J. T. (1994). Quantum mechanics: historical contingency and the Copenhagen hegemony. The University of Chicago Press, Ltd.

De Broglie, L. (1923a). Ondes et quanta. Comptes Rendus de l'Académie des Sciences de Paris, 177, 507-510.

De Broglie, L. (1923b). Quanta de lumière, diffraction et interférences. Comptes Rendus de l'Académie des Sciences de Paris, 177, p. 548-550.

De Broglie, L. (1923c). Les quanta, la théorie cinétique des gaz et le principe de Fermat. Comptes Rendus de l'Académie des Sciences de Paris, 177, 630-632.

De Broglie, L. (1923d). Waves and quanta. Nature Magazine, 112, 540-540. https://doi. org/10.1038/112540a0

De Broglie, L. (1924). A tentative theory of light quanta. Philosophical Magazine, 47, 446-458.

De Broglie, L. (1925). Recherches sur la théorie des Quanta. Annales de Physique, 10(3), 22-128. https://doi.org/10.1051/anphys/192510030022

De Broglie, L. (1927). La mécanique ondulatoire et la structure atomique de la matière et du rayonnement. Journal de Physique et le Radium, 8(5), 225-241. https://doi. org/10.1051/jphysrad:0192700805022500

De Broglie, L. (1958). Physics and Metaphysics. Nature Magazine, 181, 1814-1814. https://doi.org/10.1038/1811814a0

Dürr, S., Nonn, T., \& Rempe, G. (1998). Origin of quantum-mechanical complementarity probed by a 'which-way' experiment in an atom interferometer. Nature Magazine, 395, 33-37. https://doi.org/10.1038/25653

Forato, T. C. M., Martins, R. A., \& Pietrocola, M. (2011). Historiografia e natureza da ciência na sala de aula. Caderno Brasileiro de Ensino de Física, 28(1) 27-59. https://doi. org/10.5007/2175-7941.2011v28n1p27

Geertz, C. (2008). As interpretações das culturas. Guanabara.

Gilbert, W. (1893). De Magnete. (P. F. Mottelay, Trad.). (Trabalho original publicado em 1600). https:/www.lancaster.ac.uk/fass/projects/gilbert/docs/ onloadstonemagne00gilbuoft.pdf 
Goellner, S. V., Fraga, A. B., Filho, A. R. R., \& Mazo, J. Z. (2010). Pesquisa qualitativa na educação física brasileira: Marco teórico e modos de usar. Revista da Educação Física (UEM), 21(3), 381-410.

Guerra, A., Braga M., \& Reis J. C. (2004). Uma abordagem histórico-filosófica para o eletromagnetismo no ensino médio. Caderno Brasileiro de Ensino de Física, 21(2), 224248. https://doi.org/10.5007/\%25x

Hagstrom, W. O. (1975). The Scientific Community. Arcturus books.

Hin, L. T. W., \& Subramaniam, R. (2009). Scientific academies and scientific societies as agents for promoting science culture in developing countries. International Journal of Technology Management, 46(1,2), 132-145. https://doi.org/10.1504/IJTM.2009.022681

Hobsbawm, E. (1994). Era dos extremos. O breve século XX - 1914-1991. Editora Schwarcz.

Höttecke, D., \& Silva, C. C. (2011). Why implementing history and philosophy in school Science education is a challenge: An analysis of obstacles. Science \& Education, 20, 293316. https://doi.org/10.1007/s11191-010-9285-4

Irzik, G., \& Nola, R. (2011). A family resemblance approach to the nature of science for Science education. Science \& Education, 20(7,8) 591-607. https://doi.org/10.1007/ s11191-010-9293-4

Jardim, W., \& Guerra, A. (2017). República das Letras, Academias e Sociedades Científicas no século XVIII: A garrafa de Leiden e a ciência no ensino. Caderno Brasileiro de Ensino de Física, 34(3), 774-797. https://doi.org/10.5007/2175-7941.2017v34n3p774

Latour, B. (2001). A esperança de Pandora. EDUSC.

Latour, B. (2011). Ciência em ação: como seguir cientistas e engenheiros sociedade afora. (2. ed.). Unesp.

Latour, B. (2012). Reagregando o Social. Uma introdução à teoria do Ator-rede. EDUSC.

Latour, B. (2013). Jamais Fomos Modernos. (3. ed.). Editora 34.

Latour, B., \& Woolgar. (1997). A vida de laboratório: a produção dos fatos científicos. Relume Dumará.

Lederman, N. G. (2007). Nature of science: Past, present, and future. In S. K. Abell, \& N. G. Lederman (Eds.), Handbook of Research on Science Education (831-879). Lawrence Erlbaum Associates.

Lederman, N. G., \& Lederman, J. S. (2019). Teaching and Learning of Nature of Scientific Knowledge and Scientific Inquiry: Building Capacity through Systematic ResearchBased Professional Development. Journal of Science Teacher Education, 1-26. http://doi. org/10.1080/1046560x.2019.1625572 
Lima, N. W., Ostermann, F., \& Cavalcanti, C. J. H. (2018). A não-modernidade de Bruno Latour e suas implicações para a Educação em Ciências. Caderno Brasileiro de Ensino de Física, 35(2), 367-388. https://doi.org/10.5007/2175-7941.2018v35n2p367

Lima, N. W., Nascimento, M. M., Ostermann, F., \& Cavalcanti, C. J. H. (2020). Louis de Broglie's wave-particle duality: From textbooks blackboxes to a chain of reference presentation. Revista Brasileira de Ensino de Física (online), 42, e20190134. https://doi. org/10.1590/1806-9126-rbef-2019-0134

Lüdke, M., \& André, M. E. D. A. (1986). Pesquisa em educação: abordagens qualitativas. EPU.

Martins, A. F. (2007). História e Filosofia da Ciência no ensino: Há muitas pedras nesse caminho... Caderno Brasileiro de Ensino de Física, 24(112), 112-131. https://doi. org $/ 10.5007 / \% 25 \mathrm{x}$

Martins, A. F. P. (2015). Natureza da Ciência no ensino de ciências: Uma proposta baseada em "temas" e "questões". Caderno Brasileiro de Ensino de Física, 32(3), 703-737. https://doi.org/10.5007/2175-7941.2015v32n3p703

Martins, R., \& Rosa, P. (2014). História da teoria quântica - a dualidade onda-partícula, de Einstein a De Broglie. Livraria da Física.

Matthews, M. R. (1994). Science Teaching: The Role of History and Philosophy of Science. Routledge.

Mehra, J., \& Rechenberg, H. (1982). The Historical Development of Quantum Theory. The Quantum Theory of Planck, Einstein, Bohr and Sommerfeld: Its Foundation and the Rise of Its Difficulties 1900-1925. (Vol. 1.). Springer.

Milne, C. (2011). The Invention of Science: Why History of Science Matters for the Classroom. Sense Publishers.

Moura, C. B. (2019). Educação científica, história cultural da ciência e currículo: articulações possíveis. (Tese de Doutorado em Ciência, Tecnologia e Educação). Centro Federal de Educação Tecnológica Celso Suckow da Fonseca, CEFET/RJ, Rio de Janeiro, RJ.

Moura, C. B., \& Guerra, A. (2016). História cultural da ciência: um caminho possível para a discussão sobre as práticas científicas no ensino de ciências? Revista Brasileira de Pesquisa em Educação em Ciências, 16(3), 725-748.

Ostermann, F., \& Moreira, M. A. (2000). Uma revisão bibliográfica sobre a área de pesquisa "Física Moderna e contemporânea no ensino médio". Investigações em Ensino de Ciências, 5(1), 23-48.

Peron, T. S. (2014). História e Filosofia da Ciência e a abordagem do Método Científico. In III Conferência latinoamericana del international, history and philosophy of science teaching group IHPST- LA (p.299-309). Santiago. 
Peron, T. S., \& Guerra, A. (2017). A História Cultural da Ciência, cinema e o ensino das leis de Newton. Ensenanza de Las Ciencias, volume extra, 3809-3815.

Peron, T. S., Guerra, A., \& Forato, T. C. M. (2011). Contextualizando Galileu: Um possível caminho para abordar natureza da ciência em sala de aula. In Atas do VIII Encontro Nacional de Pesquisa em Educação em Ciências (ENPEC) (p. 1-12). Campinas, SP.

Pessoa Jr, O. (2003). Conceitos de Física Quântica. (1a ed.). Editora Livraria da Física.

Pimentel, J. (2010). ¿Qué es la historia cultural de la ciencia? Arbor, 186(743), 417-424. https://doi.org/10.3989/arbor.2010.743n1206

Prown, J. D. (1982). Mind in Matter: An Introduction to Material Culture Theory and Method. Spring, Winterthur Portfolio, 17(1), 1-19.

Rosa, P. S. (2004). Louis de Broglie e as ondas de matéria. Dissertação de mestrado. UNICAMP, IFGW. Campinas, SP.

Santos, B. S., \& Meneses, M. (2010). Introdução. In B. S. Santos, \& M. Meneses, (Orgs.) Epistemologias do Sul. (9-20). Almedina.

Santos, M. (2018). Uso da História da Ciência para Favorecer a Compreensão de Estudantes do Ensino Médio sobre Ciência. Revista Brasileira de Pesquisa em Educação em Ciências, 18(2), 641-668. https://doi.org/10.28976/1984-2686rbpec2018182641

Schiffer, H., \& Guerra, A. (2015). Electricity and Vital Force: Discussing the Nature of Science Through a Historical Narrative. Science \& Education (Dordrecht), 24, 409-434. https://doi.org/10.1007/s11191-014-9718-6

Schmidt, D. G. (2008). Erwin Schrödinger: A compreensão do mundo infinitesimal através de uma realidade ondulatória. (Dissertação de mestrado, Pontifícia Universidade Católica de São Paulo).

Schrödinger, E. (1926). Über das Verhältnis der Heisenberg-Born-Jordanschen Quantenmechanik zu der meinem. Annalen der Physik, 384(4), 361-376. https://doi. org/10.1002/andp.19263840404

Schrödinger, E. (1926). An Undulatory Theory of the Mechanics of Atoms and Molecules. Physical Review, 28(6), 1049-1070. https://doi.org/10.1103/PhysRev.28.1049

Stark, J. (1907). Elementarquantum der Energie, Modell der negativen und positiven Elektrizität. Physikalische Zeitschrift, 8, 881-884. https://archive.org/details/ physikalischeze00unkngoog

Tedesco, J. C. (2006). Prioridade ao ensino de ciências: Uma decisão política. Madri: OEIOrganização dos Estados Ibero-americanos para a Educação, a Ciência e a Cultura.

Whitley, R. (1972). Black boxism and the sociology of science: a discussion of the major developments in the field. Sociological Review, 18, 61-92. https://doi.org/10.1111/j.1467954X.1970.tb03176 
Thiago Silva Peron

Instituto Federal do Sudeste de Minas Gerais (IF Sudeste MG) Juiz de Fora, Minas Gerais, Brasil thiago.peron@ifsudestemg.edu.br

(1) Andreia Guerra

Centro Federal de Educação Tecnológica Celso Suckow da Fonseca (CEFET/RJ) Rio de Janeiro, Rio de Janeiro, Brasil andreia.guerra96@gmail.com

Editor Responsável

Alessandro Damásio Trani Gomes

Manifestação de Atenção às Boas Práticas Científicas e de Isenção de Interesse

Os autores declaram ter cuidado de aspectos éticos ao longo do desenvolvimento da pesquisa bem como declaram não ter qualquer interesse concorrente ou relações pessoais que possam ter influenciado o trabalho relatado no texto. 